\title{
ABSORPTION, REFLECTION, AND DISPERSION CONSTANTS OF QUARTZ
}

\author{
By W. W. Coblentz
}

An accurate knowledge of the transmission of quartz in the infra-red is essential in order to determine spectral energy curves of a black body with a quartz prism. As mentioned elsewhere, the program of investigation ${ }^{1}$ of the radiation constants of a black body includes the employment of a quartz prism, which has a much larger dispersion than fluorite. Unfortunately, unlike fluorite, the absorption in quartz becomes quite marked at $2 \mu$ and is practically complete beyond $3 \mu$. However, for the spectral region from the remote ultra-violet $(0.25 \mu)$ to $1.7 \mu$ in the infrared, quartz has the remarkable property of practically perfect transparency for the thicknesses $(3 \mathrm{~cm})$ which are ordinarily used in optical investigations. This is illustrated in the present research, where it is shown that after eliminating the losses for reflection at the interface, quartz air, the transmission is roo per cent, if we admit an error of 2 parts in rooo. This property of great transparency in one spectral region, and great opacity in a closely adjoining region, requires the employment of thick samples of quartz in order to determine accurately the transmission in the intervening region. The whole investigation requires a special procedure, which one would not ordinarily undertake. The data obtained in the present investigation are therefore published with the hope that they may be of use to others.

A preliminary ${ }^{2}$ examination of several samples of quartz was recently published. One sample consisted of two plates, each $6.5 \mathrm{~mm}$ in thickness. Inadvertently, as published, the thickness is stated to be $13 \mathrm{~mm}$, with no mention that it represented two 
plates. This explains the low transmission, caused by the four reflecting surfaces, as shown in the present paper, Fig. I, curve $a$, where these data are reproduced. A second sample used in the preliminary examination consisted of a quartz prism, the ends of which were polished, through which the light passed, thus giving a layer $52 \mathrm{~mm}$ in thickness. The transmission (uncorrected for surface reflection) through this prism, given in Fig. I, curve $b$, is of the order of 91.5 per cent, in the region of $\mathrm{I} \mu$, which is the value found in the present work, using other material.

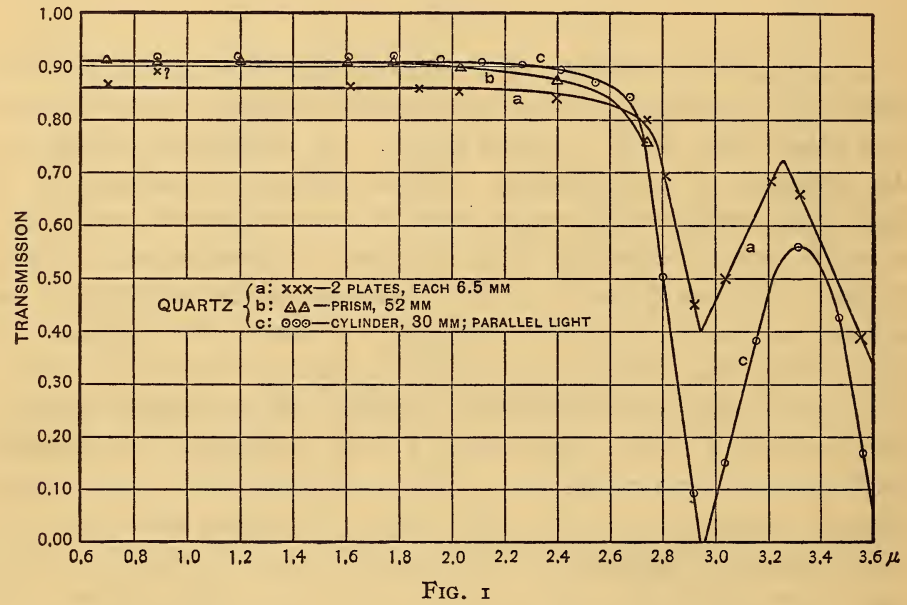

In the preliminary test the source of radiation (a Nernst glower) was placed at a distance of about ro $\mathrm{cm}$ from the spectrometer slit, through which the light passed, forming a narrow (8 to $10 \mathrm{~mm}$ wide) somewhat divergent beam upon the collimating mirror of the spectrometer. The quartz samples stood close in front of the spectrometer slit. The accuracy attained in the observations was not very high ( $\mathrm{I}$ per cent), owing to unsteadiness of the bolometer. In view of the fact that the light was not parallel ${ }^{3}$

\footnotetext{
3 This, however, could do but little more than shorten the optical path. By actual measurement no variation in the width of the cone of light falling upon the collimating mirror could be detected when the thick quartz plate (the prism with polished ends) was placed before the slit. In the present research a mirror spectrometer fluorite prism and vacuum bolometer were used, as described in previous papers.
} 
and that the transmission was not taken along the optic axis of the prism the investigation was undertaken anew, using two especially prepared cylinders of clear quartz. One cylinder was $50 \mathrm{~mm}$ in diameter and $29.925 \mathrm{~mm}$ in length. The faces were cut at an angle of about $40^{\circ}$ to the optic axis and they had an unusually fine polish. The faces were plane to a fraction of a wave length of light, and they were parallel to within $I^{\prime}$ of arc. This sample of quartz was perfectly free from smokiness, except at the extreme edge, which was shielded from radiation.

The second cylinder of quartz was $50 \mathrm{~mm}$ in diameter and $27.915 \mathrm{~mm}$ in thickness. The faces were cut perpendicular to the axis to within $49.5^{\prime} \pm 0.5^{\prime}$, the error in plane parallelism being about $0.5^{\prime}$. This sample also showed faint traces of smokiness near the edge which was covered. The faces were not quite so highly polished as the first sample, which may account for the lower transmission (greater scattering) in the visible spectrum.

The source of energy was a seasoned Nernst glower operated on a storage battery. Fortunately, the observations happened to come on several calm, cloudy days, when the vacuum bolometer and galvanometer were perfectly steady, and the glower likewise was not affected by air currents. The rays from the glower were made parallel by means of a $50-\mathrm{cm}$ focal length silvered mirror, and thence passed to a second mirror, $90 \mathrm{~cm}$ in focal length, which brought the rays to focus upon the spectrometer slit. A blackened diaphragm having an opening of about 3 by $3.5 \mathrm{~cm}$ was placed in the path of parallel rays. The quartz cylinder was mounted upon a suitable stage, sliding black and forth, close to and in the rear of the diaphragm (i. e., between the diaphragm and the second mirror). The ratio of the galvanometer deflection, observed when the quartz plate was over the opening in the diaphragm, to the deflection caused by the rays passing through the diaphragm without obstruction by the quartz, gave the transmission ( $T r$, Table $\mathrm{I}$ ). Atmospheric disturbances were unusually small, so that the galvanometer could be read to o.I mm, thus producing an accuracy of several parts in rooo instead of a few parts in Ioo, which is the usual record of radiometric work.

The transmission curve, $c$, is given in Fig. $\mathrm{r}$, and the observations $(T r)$ are given in columns 3 and 6 of Table $I$. In the transparent 
region to $1.6 \mu$ the transmission is about 91.5 per cent, as previously observed on the prism which was almost twice as thick, with the (divergent) rays passing across the optic axis. Eliminating surface reflection from the observations on the two thin plates, previously investigated, curve $a$, Fig. I, the data are in agreement with those of the thick plates.

In Table I, columns 4 and 7 , are given the true transmissions, $T_{o}$, of these two plates of quartz. These values are obtained by applying the well-known Fresnel formula for vitreous reflection, $R=\left(\frac{n-1}{n+1}\right)^{2}$ where $n$ is the refractive index. The refractive indices (Table 3) of Carvallo and of Paschen were used.

TABLE 1

\section{Transmission of Quartz}

\begin{tabular}{|c|c|c|c|c|c|c|c|}
\hline \multirow{2}{*}{$\lambda$ in $\mathrm{mm}$} & \multirow{2}{*}{$\begin{array}{c}\text { Reflection } \\
\text { correction } \\
(1-\mathbf{R})^{2} \\
\left(1+\mathbf{R}^{2}\right)\end{array}$} & \multicolumn{3}{|c|}{ Quartz cylinder $(t=29.925 \mathrm{~mm})$} & \multicolumn{3}{|c|}{ Quartz cylinder $(t=27.915 \mathrm{~mm})$} \\
\hline & & $\underset{\text { (observed) }}{\mathbf{T}_{\mathbf{r}}}$ & $\mathbf{T}_{\mathrm{o}}$ & - $\mathbf{T}_{\mathrm{o}^{1}}$ & $\underset{\text { (observed) }}{\mathbf{T}_{\mathbf{r}}}$ & $\mathbf{T}_{\mathrm{o}}$ & $T_{0}{ }^{1}$ \\
\hline 0.0005893 & 0.9125 & 0.9060 & 0.9929 & 0.9960 & 0.9055 & 0.9923 & 0.9958 \\
\hline .0008820 & .9143 & .9112 & .9966 & .9997 & .9070 & .9920 & .9955 \\
\hline .0011971 & .9153 & .9145 & .9991 & 1.0022 & . & ....... & ........ \\
\hline .0016132 & .9167 & .9138 & .9969 & 1.0000 & .9135 & .9966 & 1.0000 \\
\hline .0017835 & .9173 & .9143 & .9967 & .9998 & .9140 & .9964 & .9999 \\
\hline .0019518 & .9179 & .9120 & .9936 & .9967 & .9126 & .9942 & .9976 \\
\hline .0021128 & .9185 & .9092 & .9898 & .9929 & .9106 & .9914 & .9948 \\
\hline .0022654 & .9192 & .9037 & .9831 & .9862 & .9050 & .9846 & .9880 \\
\hline .0024098 & .9199 & .8967 & .9748 & .9778 & .8979 & .9761 & .9795 \\
\hline .0025458 & .9206 & .8720 & .9473 & .9502 & .8766 & .9522 & .9555 \\
\hline .0026120 & .9209 & ............. & .......... & ….... & .8626 & .9367 & .9399 \\
\hline .0026757 & .9213 & .8445 & .9168 & .9195 & .8512 & .9239 & .9272 \\
\hline .0027392 & .9216 & ............... & ........ & .......... & .7757 & .8417 & .8446 \\
\hline .0028010 & .9219 & .5050 & .5477 & .5494 & .5319 & .5769 & .5789 \\
\hline .0029213 & .9227 & .0917 & .0994 & .0997 & .0748 & .0811 & .0814 \\
\hline .0030373 & .9234 & .153 & & ....... & .1426 & .1544 & .1549 \\
\hline .0031501 & ................ & .384 & & & .3776 & & $\ldots .$. \\
\hline .0033132 & .............. & .560 & & & .5558 & . & $\cdots$. \\
\hline .0034190 & (............. & ....... & & & .5285 & & \\
\hline .0034700 & - & .430 & & & .4573 & & \\
\hline .0035690 & -. & .171 & & & .1895 & 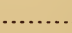 & \\
\hline
\end{tabular}

The radiation contributed by two reflections $R^{2}(\mathrm{r}-R)^{2}$ within the quartz plate is negligible in most work. If there were no errors of observation and no scattering of light, the values should be 
$T_{0}=\mathrm{I}$ in the spectral region where there is no absorption. From the present observations this appears to be true to about 2 parts in 1000 for the region of transparency from 0.6 to $\mathrm{I} .8 \mu$. The fifth and eighth columns of Table I give the transmission $T_{0}$ on the assumption that there is perfect transmission up to and at $\lambda=\mathrm{r} .6 \mathrm{r} 32 \mu$, i. e., all the observed values are divided by 0.9969 , which is the observed value, $T_{o}$, at $\lambda=1.6132 \mu$. The deviations from $T_{0}=\mathrm{I}$ are then found to be far smaller than the average experimental errors which usually enter into such work.

TABLE 2

Transmission of Quartz-Extinction Coefficient

\begin{tabular}{|c|c|c|c|}
\hline$\lambda$ in $\mathbf{m m}$ & $\begin{array}{l}\text { Quartz cylinder } \\
(\mathrm{t}=29.925 \mathrm{~mm}) K\end{array}$ & $\begin{array}{l}\text { Quartz cylinder } \\
(\mathrm{t}=27.915 \mathrm{~mm})\end{array}$ & $\kappa-$ Mean value \\
\hline 0.0016132 & 0.000000009 & 0.000000010 & 0.000000009 \\
\hline .0017835 & .000000010 & .000000012 & .000000011 \\
\hline .0019518 & .000000022 & .000000021 & .000000022 \\
\hline .0021128 & .000000038 & .000000035 & .000000037 \\
\hline .0022654 & .000000068 & .000000066 & .000000067 \\
\hline .0024098 & .000000108 & .000000109 & .000000109 \\
\hline .0025458 & .000000243 & .000000235 & .000000239 \\
\hline .0026120 & ............ & .000000323 & .000000323 \\
\hline .0026757 & .000000410 & .000000400 & .000000405 \\
\hline .0027392 & 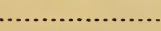 & .000000894 & .000000894 \\
\hline .0028010 & .00000298 & .00000292 & .00000295 \\
\hline
\end{tabular}

In passing it is desirable to record the very marked reflection caused by fine particles of dust. One sample of quartz, which had stood uncovered for a day, transmitted over I per cent (depending upon the wave length) less than the usual value ( 89.8 instead of 9I.35 per cent). Examined in front of a bright incandescent lamp, the surfaces showed faint tarnishing and dust. After thoroughly polishing the surfaces with a soft cloth the normal transmission (9I.4 per cent) was again observed.

The absorption index (extinction coefficient) $\kappa$ is computed from the equation $A=\mathrm{I}-e^{-a l}$, where $a=4 \pi \frac{n \kappa}{\lambda}$. Here the thickness, $l$, of the piate and the wave length, $\lambda$, are in millimeters. The data for the two samples, computed from columns 4 and 7 of 
Table $\mathrm{I}$, are given in Table 2 , the values being in close agreement where the true absorption of quartz becomes important. A large absorption band of quartz occurs at $2.95 \mu$; and a small depression at $2.6 \mu$ (see Fig. 2) was observed in the transmission of both samples of quartz. The sample of quartz, 27.91 $5 \mathrm{~mm}$ in thickness, was not so highly polished as the first specimen. This would cause more scattering of light, and an apparently high extinction coefficient, especially in the visible spectrum.

TABLE 3

\section{Quartz Reflection}

[In this table $R$ is the reflection which occurs at normal incidence and $R_{1}$ and $R_{2}$ are the reflection coefficients for light polarized respectively in and perpendicular to the plane of incidence. ]

\begin{tabular}{|c|c|c|c|c|c|c|c|}
\hline$\lambda$ & $(1-R)^{2}\left(1+R^{2}\right)$ & $\frac{\left(1-\mathbf{R}_{1}\right)^{2}+\left(1-\mathbf{R}_{2}\right)^{2}}{2}$ & $\begin{array}{l}\text { Refrac- } \\
\text { tive } \\
\text { index }\end{array}$ & $\lambda$ & $(1-R)^{2}\left(1+R^{2}\right)$ & $\frac{\left(1-\mathbf{R}_{1}\right)^{2}+\left(1-\mathbf{R}_{2}\right)^{2}}{2}$ & $\begin{array}{l}\text { Refrac- } \\
\text { tive } \\
\text { index }\end{array}$ \\
\hline $0.325 \mu$ & 0.9062 & 0.8668 & 1.57094 & 1.0417 & & 0.8821 & 1.53442 \\
\hline .340 & .9069 & 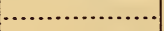 & 1.56744 & 1.0715 & 0.9149 & ....... & 1.53402 \\
\hline .3582 & .9077 & & 1.56400 & 1.1592 & .... & .8827 & 1.53283 \\
\hline .361 & .9078 & ....... & 1.56348 & 1.2215 & .9154 & $\cdots \cdot$ & 1.53201 \\
\hline .396 & .9091 & .8722 & 1.55815 & 1.3070 & $\ldots$. & .8835 & 1.53090 \\
\hline .4046 & .9094 & . & 1.55706 & 1.376 & .9159 & ....... & 1.53001 \\
\hline .410 & .9095 & $\ldots$. & 1.55649 & 1.4219 & ....... & .8842 & 1.52942 \\
\hline .434 & .9101 & .8740 & 1.55396 & 1.528 & .9164 & ........ & 1.52800 \\
\hline .4862 & .9113 & $\ldots .$. & 1.54964 & 1.5414 & ..... & .8848 & 1.52781 \\
\hline .508 & .9115 & .8764 & 1.54822 & 1.670 & .9169 & ….... & 1.52602 \\
\hline .5349 & .9119 & ....... & 1.54663 & 1.6815 & ...... & .8856 & 1.52583 \\
\hline .5893 & .9125 & .8780 & 1.54420 & 1.7614 & ....... & .8860 & 1.52468 \\
\hline .6158 & .9127 & .8785 & 1.54323 & 1.870 & .9176 & ...... & 1.52302 \\
\hline .643 & .9129 & .8789 & 1.54226 & 1.9457 & ....... & .8872 & 1.52184 \\
\hline .6563 & .9130 & 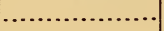 & 1.54182 & 1.999 & .9181 & & 1.52100 \\
\hline .6678 & .9131 & $\ldots . .$. & 1.54155 & 2.170 & .9188 & & 1.51802 \\
\hline .686 & .9133 & .8794 & 1.54097 & 2.1719 & ..... & .8886 & 1.51799 \\
\hline .7065 & .9134 & ...... & 1.54048 & 2.3573 & $\ldots .$. & .8900 & 1.51449 \\
\hline .7435 & .9136 & ...... & 1.53956 & 2.384 & .9198 & & 1.51403 \\
\hline .760 & .9137 & .8802 & 1.53917 & 2.574 & .9207 & $\ldots .$. & 1.51002 \\
\hline .7682 & .9138 & & 1.53890 & 2.6519 & ...... & .8925 & 1.50824 \\
\hline .7711 & .9138 & ....... & 1.53895 & 2.746 & .9216 & . & 1.50602 \\
\hline .8007 & .9139 & .8805 & 1.53835 & 2.7993 & $\ldots$. & .8938 & 1.50474 \\
\hline .8325 & .9141 & . & 1.53773 & 2.904 & .9226 & & 1.50201 \\
\hline .8671 & .9142 & .8810 & 1. 53711 & 3.058 & .9235 & $\ldots$ & 1.49800 \\
\hline .9047 & ....... & .8813 & 1.53649 & 3.0939 & & .8967 & 1.49703 \\
\hline .9335 & .9145 & & 1.53600 & & & & \\
\hline
\end{tabular}


The factors for eliminating the absorption in a wedge of quartz are determined from the equation ${ }^{4}$

$$
\frac{I_{0}}{I}=\frac{\log (\mathrm{I}-A)^{B / l}}{\left[(\mathrm{I}-A)^{B / l}-\mathrm{I}\right] \log \epsilon} .
$$

It is derived from an integration of the equation

$$
I=\frac{I_{0}}{h} \int_{0}^{h} \epsilon^{-a \frac{B}{h} x} d x .
$$

In these equations $A$ is the absorption ( $\mathrm{I}-T_{o}$ ) observed in the quartz plate and $l$ is its thickness $(29.925 \mathrm{~mm}) ; B$ is the thickness of the back of the prism (i. e., the width of the face, $52 \mathrm{~mm}$, which is opposite the refracting angle); and $h$ is the vertical height of the refracting edge from the back of the prism. The observed intensity (in galvanometer deflections), is $I$; and $I_{o}$ is the true intensity of the radiations emanating from the source.

\section{TABLE 4}

Factors for Eliminating the Effect of Absorption in a Prism Having a Base (Back

\begin{tabular}{|c|c|c|c|c|}
\hline \multirow{2}{*}{$\lambda$ in $\mathrm{mm}$} & \multicolumn{4}{|c|}{ Factor } \\
\hline & $\mathrm{t}=29.925 \mathrm{~mm}$ & $\mathrm{t}=27.915 \mathrm{~mm}$ & Mean & $\frac{\text { Mean }}{1.003}$ \\
\hline 0.0016132 & 1.0028 & 1.0032 & 1.0030 & 1.0000 \\
\hline .0017835 & 1.0029 & 1.0034 & 1.0032 & 1.0002 \\
\hline .0019518 & 1.0057 & 1.0055 & 1.0056 & 1.0026 \\
\hline .0021128 & 1.0089 & 1.0082 & 1.0086 & 1.0056 \\
\hline .0022654 & 1.0150 & 1.0147 & 1.0149 & 1.0119 \\
\hline .0024098 & 1.0226 & 1.0229 & 1.0228 & 1.0197 \\
\hline .0025458 & 1.0483 & 1.0467 & 1.0475 & 1.0444 \\
\hline .0026120 & ........... & 1.0628 & 1.0628 & 1.0596 \\
\hline .0026757 & 1.078 & 1.076 & 1.077 & 1.074 \\
\hline .0027392 & ........... & 1.117 & 1.117 & 1.114 \\
\hline .0028010 & 1.619 & 1.605 & 1.612 & 1.607 \\
\hline
\end{tabular}
Face) of 50 to $52 \mathrm{~mm}$ in Width

In Fig. 2 curve $A$, gives the true transmission ( $T_{o}$ of Table $\mathrm{r}$ ) of the thickest plate of quartz. The absorption begins at $r .8 \mu$. Curve $B$, Fig. 2, gives the factors to be used in eliminating the effect of this absorption in a prism, the back face of which is 50 to $52 \mathrm{~mm}$ in thickness. Numerical data for eliminating this absorption, which begins at about $1.9 \mu$, are given in Table 4 . This table shows 
that, for example, at $2.739 \mu$ the observed intensity must be increased by II.4 per cent in order to correct for the loss by absorption in the prism. The last column in Table 4 gives the correction for absorption in the prism on the assumption that the error of the present observation is 0.3 per cent. It is obtained by dividing all the mean values by 1.003 .

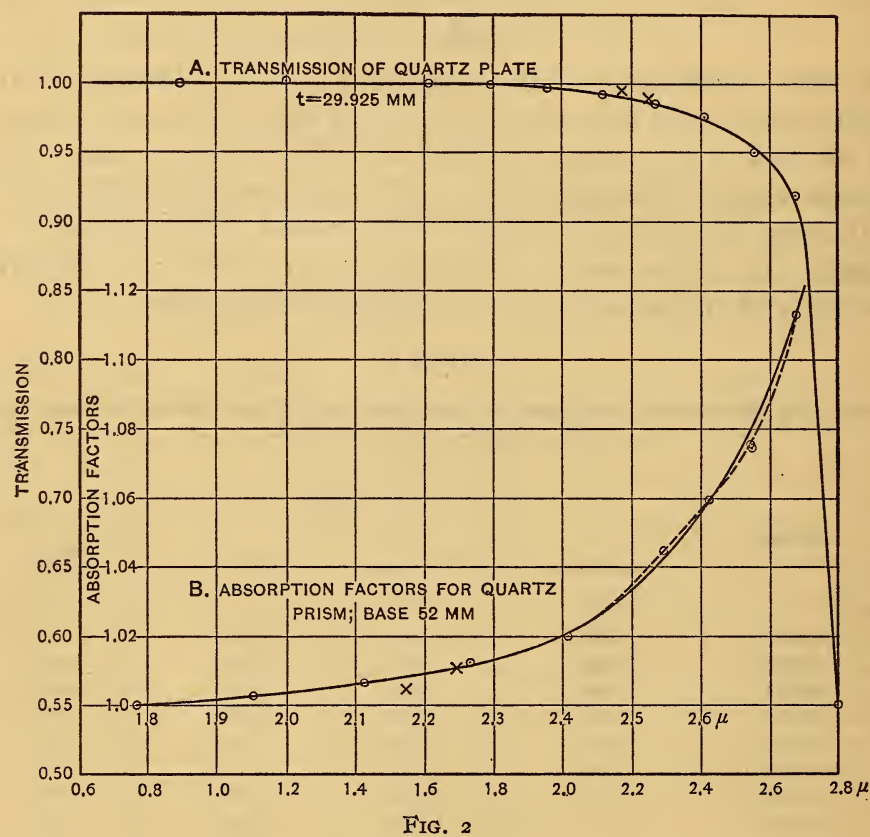

A further increase in the value of $I$ is, of course, necessary for the loss by reflection from the prism faces with variation in the angle of incidence which is required in order to cause the rays to pass through the prism at minimum deviation. The values for reflection were computed by means of the Fresnel formulas,

$$
R_{1}=\frac{\sin ^{2}(i-r)}{\sin ^{2}(i+r)} \quad R_{2}=\frac{\operatorname{tang}^{2}(i-r)}{\operatorname{tang}^{2}(i+r)},
$$


which give the variation in reflection with variation in the angle of incidence. The angles of incidence used in this computation are those required in order that the rays will pass at minimum diviation through a quartz prism having an angle of $59^{\circ} 5 \mathrm{I}^{\prime} 2 \mathrm{I}^{\prime \prime}$. These values may be used without serious errors with a prism having a refracting angle which differs by $5^{\prime}$ to $6^{\prime}$ from the one used in the present computations. The numerical data for eliminating the variation in reflection with variation in angle of incidence are given in column 3 of Table 3 . For a prism having a refracting angle of $60^{\circ}$ the values should be decreased by 0.0005 .

If the spectral energy measurements are made with a radiometer which is covered with a quartz window then a still further correction for reflection (also for absorption) must be made to the observations. This correction for reflection is the same as the one applied in determining the transmission of quartz. The numerical values for correcting for the reflection from a quartz window are given in column 2 of Table 3. In Fig. 2, curve B, the crosses $(X X)$ show the absorption in a plate of quartz $3.5 \mathrm{~cm}$ in thickness. They represent preliminary data, observed by Warburg ${ }^{5}$ and his associates.

To obtain an accurate calibration curve of a prism is a laborious process and these data are included in Table 5 of the present paper. The calibration curve (minimum deviation settings of the spectrometer circle and wave lengths) was computed from the refractive indices of Carvallo ${ }^{6}$ and of Paschen. ${ }^{7}$ The fiducial line is the yellow helium line; $\lambda=0.5875^{8} \mu$.

The data pertain to a quartz prism having a refracting angle of $59^{\circ} 5 \mathrm{I}^{\prime} 2 \mathrm{I}^{\prime \prime}$. Hence, for a prism having a considerably different angle the wave lengths will be found to be in error. However, the "slit-width factors" for reducing an energy curve from prismatic to normal spectrum will not be affected by the usual deviations from a $60^{\circ}$ prism. These factors relate to a radiometer receiver $1 \mathrm{o}^{\prime}$ in width, and they may be used for slit widths at least 50 per cent different from this value. For example, the test was made for a width of $6^{\prime}$, which should give slit-width

6 Warburg, Leithäuser, Hupka, Müller, Ann. der Phys. (4), 40, p. 614; I913.

- Carvallo, Compt. Rendus, 126, p. 728; 1898.

7 Paschen, Ann. der Phys., (4), 35, p. roo5; Igrr. 
factors which are 0.6 of those given in Table 5 . By reading the wave lengths from the calibration curve for a difference of $6^{\prime}$ on the spectrometer circle, the wave lengths subtended by a radiometer, $6^{\prime}$ in width, in different parts of the spectrum were found in agreement to within 2 parts in ro ooo with the values (i. e., 0.6 of the values) in Table 5, which is as accurate as one can read the values from the calibration curve.

TABLE 5

Quartz Prism Calibration

\begin{tabular}{|c|c|c|c|c|c|c|c|c|c|c|c|}
\hline \multicolumn{2}{|c|}{$\begin{array}{l}\text { Spect. } \\
\text { setting }\end{array}$} & \multirow{2}{*}{$\begin{array}{r}\begin{array}{r}\text { Wave } \\
\text { length }\end{array} \\
\mu\end{array}$} & \multirow{2}{*}{$\frac{\substack{\text { Slit } \\
\text { width }=10^{\prime}}}{\mu}$} & \multicolumn{2}{|c|}{$\begin{array}{l}\text { Spect. } \\
\text { setting }\end{array}$} & \multirow{2}{*}{$\begin{array}{r}\begin{array}{r}\text { Wave } \\
\text { length }\end{array} \\
\mu\end{array}$} & \multirow{2}{*}{$\frac{\substack{\text { Slit } \\
\text { width }=10^{\prime}}}{\mu}$} & \multicolumn{2}{|c|}{$\begin{array}{l}\text { Spect. } \\
\text { setting }\end{array}$} & \multirow{2}{*}{$\begin{array}{r}\begin{array}{r}\text { Wave } \\
\text { length }\end{array} \\
\mu\end{array}$} & \multirow{2}{*}{$\frac{\begin{array}{c}\text { Slit } \\
\text { width }\end{array}=10^{\prime}}{\mu}$} \\
\hline 。 & ' & & & & , & & & & , & & \\
\hline+2 & 30 & 0.3206 & ....... & & 15 & 0.5269 & 0.0340 & -2 & 00 & 1.9496 & 0.1178 \\
\hline & 25 & .3242 & 0.0075 & & 10 & .5451 & .0385 & & 05 & 2. 0073 & .1148 \\
\hline & 20 & . 3281 & .0080 & & 05 & .5654 & .0425 & & 10 & 2. 0644 & .1118 \\
\hline & 15 & .3322 & .0082 & 0 & 00 & .58758 & .0465 & & 15 & 2. 1191 & 1089 \\
\hline & 10 & .3363 & .0084 & - & 05 & .6119 & .0507 & & 20 & 2. 1733 & .1061 \\
\hline & 05 & .3406 & .0089 & & 10 & .6383 & .0562 & & 25 & 2. 2252 & .1032 \\
\hline+2 & 00 & .3452 & .0093 & & 15 & .6681 & .0637 & & 30 & 2. 2765 & .1004 \\
\hline & 55 & .3500 & .0096 & & 20 & .7020 & .0717 & & 35 & 2.3256 & .0978 \\
\hline & 50 & .3550 & .0100 & & 25 & .7398 & .0808 & & 40 & 2. 3743 & .0954 \\
\hline & 45 & .3600 & .0105 & & 30 & .7828 & .0902 & & 45 & 2. 4210 & .0932 \\
\hline & 40 & .3652 & .0109 & & 35 & .8300 & .1004 & & 50 & 2. 4675 & .0914 \\
\hline & 35 & .3708 & .0118 & & 40 & .8832 & .1100 & & 55 & 2. 5124 & .0896 \\
\hline & 30 & .3764 & .0122 & & 45 & .9400 & .1193 & -3 & 00 & 2. 5571 & .0878 \\
\hline & 25 & .3827 & .0128 & & 50 & 1. 0025 & .1285 & & 05 & 2. 6002 & .0862 \\
\hline & 20 & 3889 & .0135 & & 55 & 1.0685 & .1365 & & 10 & 2. 6433 & .0845 \\
\hline & 15 & 3959 & .0144 & -1 & 00 & 1. 1390 & .1418 & & 15 & 2. 6847 & .0829 \\
\hline & 10 & .4029 & .0151 & & 05 & 1. 2103 & .1445 & & 20 & 2. 7262 & .0814 \\
\hline & 05 & .4108 & .0162 & & 10 & 1. 2835 & .1454 & & 25 & 2. 7661 & .0798 \\
\hline+1 & 00 & .4193 & .0176 & & 15 & 1. 3557 & .1444 & & 30 & 2. 8060 & .0784 \\
\hline & 55 & .4284 & .0185 & & 20 & 1.4279 & .1425 & & 35 & 2. 8445 & .0771 \\
\hline & 50 & .4378 & .0195 & & 25 & 1. 4982 & .1397 & & 40 & 2. 8831 & .0758 \\
\hline & 45 & .4479 & .0213 & & 30 & 1.5676 & .1369 & & 45 & 2. 9203 & .0746 \\
\hline & 40 & .4591 & .0226 & & 35 & 1. 6351 & .1337 & & 50 & 2. 9577 & .0735 \\
\hline & 35 & .4705 & .0239 & & 40 & 17013 & .1304 & & 55 & 2. 9938 & .0723 \\
\hline & 30 & .4830 & .0260 & & 45 & 1. 7655 & .1274 & -4 & 00 & 3. 0300 & .0712 \\
\hline & 25 & .4965 & .0281 & & 50 & 1. 8287 & .1240 & & 05 & 3. 0650 & .0703 \\
\hline & 20 & .5111 & .0304 & & 55 & 1.8895 & .1209 & & 10 & 3. 1003 & $\ldots .$. \\
\hline
\end{tabular}

The manner of obtaining the calibration curve and slit-width correction factors is given more fully elsewhere. ${ }^{8}$ In Table 5 the "spectrometer setting" is the minimum deviation setting. If 
a Wadsworth mirror-prism device is used, the angular rotation is only half as great to attain the wave length here recorded.

In conclusion, acknowledgement is due to my assistant, W. B. Emerson, for the numerous computations involved in this investigation.

\section{SUMMARY}

This paper gives quantitative data on the absorption, reflection, and dispersion of quartz, extending from the ultra-violet to $3 \mu$ in the infra-red. The data may be used in determining spectral energy curves. Quartz is practically transparent from the ultraviolet to $\mathrm{I} .8 \mu$. It begins to absorb strongly beyond $\mathrm{I} .8 \mu$, and tabulated data are given for eliminating the effect of this absorption in a quartz prism. The results show that (within the errors of observation) in unpolarized light, the transmission is not affected by the direction in which the radiations pass through the material with respect to the optic axis.

Washington, December 9, I9I3. 